\title{
Determination of the Area Prospected by a Baited Trap from a Tagging and Recapture Experiment with Snow Crabs (Chionoecetes opilio)
}

\author{
Jean-Claude Brêthes, Roxane Bouchard and Gaston Desrosiers \\ Department of Oceanography, University of Quebec (Rimouski) \\ Rimouski, Quebec, Canada G5L 3A1
}

\begin{abstract}
The area of influence of a baited trap of the type used in the southwestern Gulf of St. Lawrence snow crab fishery was studied by releasing tagged crabs at increasing distances from the bait and noting recaptures after fishing periods of 24 and $48 \mathrm{hr}$. For the shorter fishing period, the recapture rate decreased with increasing distance of released crabs from the trap. The radius of the prospected area was estimated to be in the range of 100-140 m, with the radius of the effective fished area being about 50-70 m. Resulis from the 48-hr experiment were inconclusive. The low recapture rates (maximum $5 \%$ ) and the long distances travelled by the tagged crabs (up to $3,000 \mathrm{~m}$ in $48 \mathrm{hr}$ ) lead to the belief that biological factors, inasmuch as they interfere with the simple bait stimulus-response mechanism, play an important role in variation of catch success. The results of this study also indicated that the trap's influence extends over a greater area than has been suggested in previous studies.
\end{abstract}

\section{Introduction}

Interpretation of catch success has always posed problems for fishery biologists, the fundamental question being to what extent the catch or sample of the catch is representative of the number of individuals in the fished area. The problems become very important when such data are used for stock evaluation purposes. Interpretation of data from experiments with baited traps is particularly tenuous due to the varying behavior of the researched species.

Experiments on the effectiveness of traps were conducted by Miller (1975). He attempted to estimate the area fished by the Japanese conical trap which was used in the snow crab fishery of the eastern Gulf of St. Lawrence. He defined the effective area as a function of the average catch per unit of fishing time and the density of crabs on the bottom, with the density being measured by independent techniques such as trawl surveys and bottom photography. Another method of estimating the effective area fished was described by Eggers et al. (1982) from catch data. They proposed the use of lines whereby the distance between successive traps or hooks is variable. This method permitted estimation of the distances from the traps where the effective areas ceased to overlap, thereby obtaining the radius of the effective area.

In this paper, the study involved a short-time tagging and recapture experiment with traps of the type used in the snow crab fishery of the southwestern Gulf of St. Lawrence, whereby batches of tagged crabs were released at varying distances from the trap, with the principal object of evaluating the effective fished area from the recapture rates of the crabs.
Materials and Methods

\section{General principles}

The immersion of bait in water induces a sequential catch process which has been described by Caddy (MS 1977). A schematization of this process is shown as a flowchart in Fig. 1. The bait must obviously be attractive to the species being studied. It is generally acknowledged that detection of food by decapod crustaceans is by olfaction (McLeese, 1970; Mackie, 1973; Hancock, 1974) and that the effectiveness of a bait can be determined by its ability to release diffusible chemicals, particularly amino-acids (Mackie et al., 1980). The diffusion of these chemicals must follow the general laws for diffusion of a substance in salt-water, whereby the concentration of a substance after release diminishes exponentially along a horizontal axis from the source (Talbot and Sendner, 1973). Below some threshold concentration, the animal cannot detect the chemical. According to Caddy (MS 1977), this threshold is between $10^{-4}$ and $10^{-5} \mathrm{~g} / \mathrm{l}$ for lobster (Homarus americanus). When detection reaches extinction at a distance $D_{\max }$ from the source, the bait has no more effect on the animal. The value of $D_{\max }$ indicates the limit of the influence of the trap.

Between the source of the odor and $D_{\max }$, all crabs may detect the odor but are not vulnerable to the same degree. Some animals may not be interested for various reasons: presence of other prey; immersion of the trap outside the active feeding period, diurnal feeding rhythms, or during periods of molting, migration and reproduction. When a crab is interested in the bait, it follows the bait-odor trail, as demonstrated by Miller (1981) in tank experiments. Thereafter, success of the 


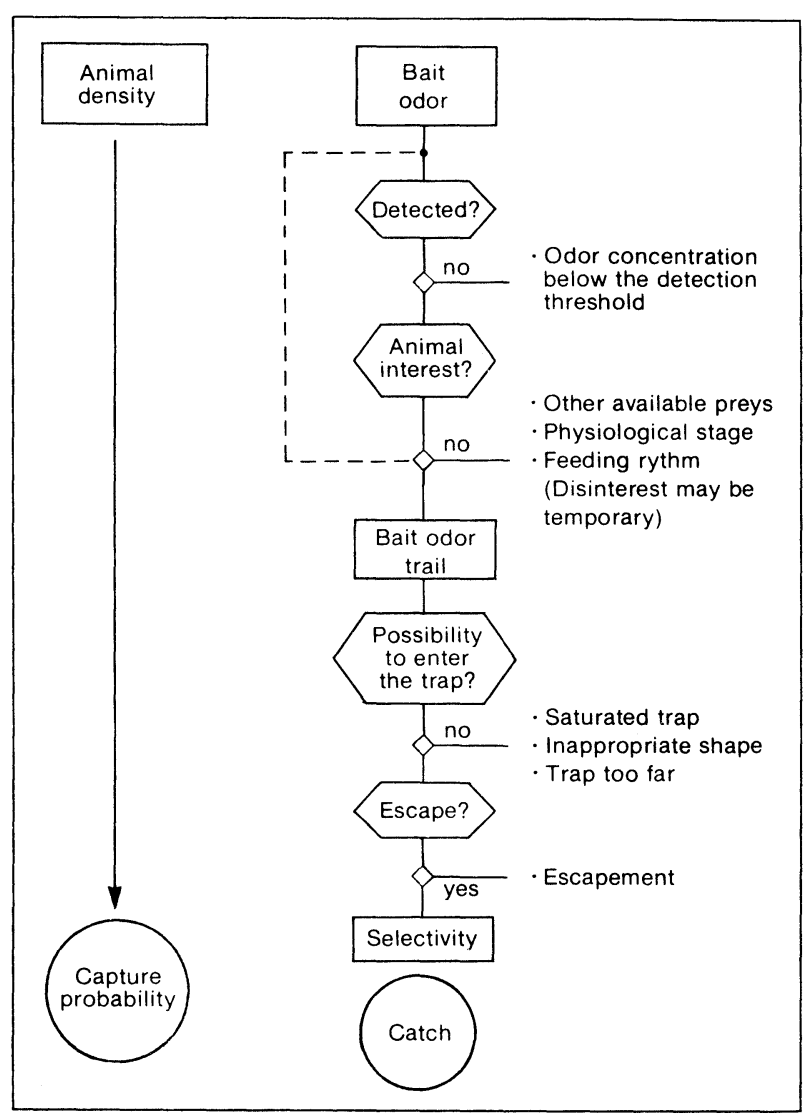

Fig. 1. General flowchart representing the process of capturing animals in a baited trap

trap will depend essentially on its shape, particularly the location of the entrance, on its saturation level (Miller, 1978, 1979), and on the aggressive behavior of other crabs around the trap (Rodhouse, 1984). Once inside the trap, the crab's escapement depends on its size and the selectivity of the gear.

The results of these diverse components may be expressed as catch probability that is associated with each individual. This probability varies as the intensity of the stimulus, associated with the odor concentration, varies. It should decrease from a maximum value $\left(P_{\max }\right)$ near the source to zero at $D_{\max }$. All individuals would be vulnerable to capture, if $P_{\max }=1$. Values of $P_{\max }$ between 0 and 1 would indicate varying degrees of vulnerability among individuals.

Two different notions should be defined here. The first is the gear's area of influence, which is a circle with radius $D_{\max }$. The other notion is the effective fished area, which corresponds to a theoretical circle of radius $D_{e}$, where all crabs have the same catch probability $\left(P_{\max }\right)$. It is this effective area that Miller (1975) and Eggers et al. (1982) tried to measure. The first notion is useful for studying the gear's influence on the population and for evaluating interactions between gears, whereas the second notion integrates better into the measurement of population size.

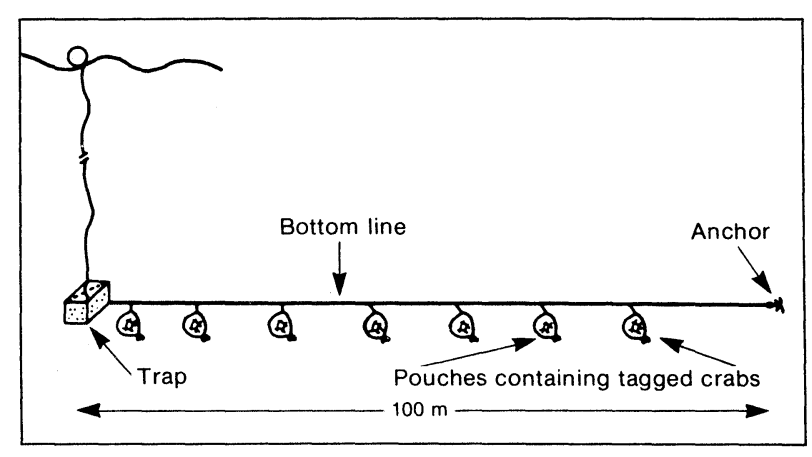

Fig. 2. Schematic representation of the gear used in the tagging experiment with snow crabs in the southwestern Gulf of St. Lawrence.

By directly comparing catch to population density, Miller (1975) implicitly assumed that all crabs were equally vulnerable to capture by the gear with $P_{\max }=1$. The method advanced by Eggers et al. (1982), in theory, leads to a measurement of the area of influence, which they equated implicitly to the effective fished area, because they assumed that all individuals present in the area have equal probability of capture. If, instead of using variable distances between units of the gear, marked animals are released at variable distances from the baited trap, it should be possible to measure both the area of influence and the effective fished area, and to observe the changes in catch probability.

\section{Methodology}

The experiment was conducted in October 1983 on muddy, gravelly bottom in the southwestern Gulf of St. Lawrence $\left(48^{\circ} 33^{\prime} \mathrm{N}, 64^{\circ} 07^{\prime} \mathrm{W}\right)$ with traps of the type used in the fishery for snow crabs (C. opilio). The trap consisted of a prism-like frame $(1.5 \times 1.5 \mathrm{~m}$ base and $0.6 \mathrm{~m}$ high) covered with $130 \mathrm{~mm}$ mesh (stretched) netting and containing two lateral opposing entrances. Although the crab fishermen are interested only in retaining male crabs larger than $95 \mathrm{~mm}$ carapace width, this study involved male crabs greater than 85 $\mathrm{mm}$.

Tagged crabs were released at known distances from the baited trap. Because the depth was greater than $100 \mathrm{~m}$ and did not permit diving operations, the crabs were lowered to the bottom in synthetic bags which were closed with a rubber bracelet and a sugarring. The ring dissolved completely after approximately 30 minutes, permitting the crabs to escape. Each crab was marked with a numbered spaghetti tag which was tied around the carapace (Watson, 1970). Seven bags were attached to a cord which extends from the trap to a grapnel (Fig. 2). Each bag contained 15 tagged crabs. Tag-induced mortality was estimated from the number of dead crabs in an additional closed bag at the end of the line when the gear was retrieved.

Two different fishing periods (time from setting to retrieval of gear) were used -24 and $48 \mathrm{hr}$. In the 
shorter fishing period, distances between the trap and successive bags were $5,15,30,45,50,55$ and $60 \mathrm{~m}$. In the longer fishing period, the last three bags were placed at 60,75 and $90 \mathrm{~m}$ from the trap. The surface area of a circle with radius $60 \mathrm{~m}$ is $11,300 \mathrm{~m}^{2}$, which is more than twice the effective fished area $\left(4,100 \mathrm{~m}^{2}\right)$ calculated by Miller (1975) from experiments on the same species with a conical trap.

Eleven sets were made for each fishing period. The bait in each trap consisted of $2 \mathrm{~kg}$ of frozen herring (Clupea harengus) or cod (Gadus morhua), for which the catch rates were not significantly different $(P>0.05)$. After each haul, the number of tagged crabs and their distances from release points were noted. Only those crabs which were caught in traps associated with their release lines were used in estimating the recapture rates. Because of the small numbers of tagged crabs that were recaptured and the variation among sets, the data for all sets with the same fishing time were combined and an overall recapture rate determined for the crabs released at each distance from the trap. The recapture rates were adjusted to account for $6 \%$ mortality due to the tagging operations.

The models used in estimating $D_{\max }$ were the simple linear regression of recapture rate on distance of release from the trap

$$
P=P_{\max }-a D
$$

and the logarithmic (base 10) transformation of the negative exponential function

$$
\log (P+1)=\log \left(P_{\max }+1\right)-b D
$$

where $P$ is recapture rate, $D$ is distance from trap, a and $b$ are regression coefficients, and parameters $P_{\max }$ and $\log \left(P_{\max }+1\right)$ are the $y$-intercepts of the regression lines. The relevant values of $D_{\max }$ are determined by setting $P=0$. If the catch probability $\left(P_{\max }\right)$ of all recaptures are assumed to the same, the radius of the effective fished area $\left(D_{e}\right)$ may be considered as being equal to $D_{\max } / 2$.

Irrespective of their release sites relative to the locations of the traps, all recaptures were considered as a multiple tag-recapture experiment, in order to estimate the size of the sampled population $(N)$ by the Schnabel method (Ricker, 1980):

$$
N=\left(\Sigma C_{t} M_{t}\right) / R
$$

where $C_{t}$ is the total number of crabs caught in period $t$, $M_{t}$ is the number of crabs released at the beginning of period $t$, and $R$ is the total number of recaptures. The variance of the reciprocal of $\mathrm{N}$ is given by

$$
V(1 / N)=R /\left(\Sigma C_{t} M_{t}\right)^{2}
$$

In order to find the density of crabs, the size of the experimental area was estimated by mapping the polygon that was formed by the points of release, the positions being plotted by radar. The resulting estimate of the surface area was $5.1 \mathrm{~km}^{2}$. The effective fished area (S) was determined from the ratio

$$
\mathrm{S}=\mathrm{C} / \mathrm{d}
$$

where $C$ is the average catch (number) and $d$ is the density (number $/ \mathrm{m}^{2}$ ). For this estimation, 170 additional tagged crabs were released at the center of the experimental area by means of a special cage (Farmer and Al-Attar, 1981), in order to avoid dispersion of the crabs by currents.

\section{Results}

The average catch of crabs in the 48-hr fishing period was slightly higher than in the $24-\mathrm{hr}$ period (Table 1), but the difference was not statistically significant $(P>0.30)$. The recapture rates of tagged crabs in both fishing periods were quite low, the maximum values being $2.6 \%$ and $5.0 \%$ for the crabs released at $5 \mathrm{~m}$ from the traps in the 24- and 48-hr periods respectively.

For the 24-hr experiment, the recapture rates were significantly correlated $(\mathrm{P}<0.05)$ with the distances of releases from the traps (Fig. 3), the correlation coefficients being approximately the same (0.78 and 0.79$)$ for the linear and logarithmic regressions. This indicates that distance of release from the bait accounted for about $60 \%$ of the variability in recapture rates. Extrapolation of the regression lines provides $D_{\max }$ estimates of 106 and $139 \mathrm{~m}$ for the linear and logarithmic models respectively. These radii define circles with surface areas of $35,300 \mathrm{~m}^{2}$ and $60,700 \mathrm{~m}^{2}$, which may be considered as estimates of the maximum surface

TABLE 1. Effective numbers of tagged crabs released at various

\begin{tabular}{|c|c|c|c|c|c|c|}
\hline \multirow{3}{*}{$\begin{array}{l}\text { Distance } \\
\text { from trap } \\
(\mathrm{m})\end{array}$} & \multicolumn{3}{|c|}{ 24-hr fishing period } & \multicolumn{3}{|c|}{ 48-hr fishing period } \\
\hline & \multirow{2}{*}{$\begin{array}{l}\text { Number } \\
\text { tagged }\end{array}$} & \multicolumn{2}{|c|}{ Recaptured } & \multirow{2}{*}{$\begin{array}{l}\text { Number } \\
\text { tagged }\end{array}$} & \multicolumn{2}{|c|}{ Recaptured } \\
\hline & & No. & $\%$ & & No. & $\%$ \\
\hline 5 & 155 & 4 & 2.6 & 141 & 7 & 5.0 \\
\hline 15 & 155 & 3 & 1.9 & 127 & 1 & 0.8 \\
\hline 30 & 155 & 2 & 1.3 & 141 & 2 & 1.4 \\
\hline 45 & 154 & 2 & 1.3 & 155 & 1 & 0.7 \\
\hline 50 & 155 & 3 & 1.9 & - & - & - \\
\hline 55 & 155 & 2 & 1.3 & - & - & - \\
\hline 60 & 154 & 1 & 0.6 & 155 & 3 & 1.9 \\
\hline 75 & - & - & - & 155 & 1 & 0.7 \\
\hline 90 & - & - & - & 154 & 3 & 1.9 \\
\hline Total & 1,083 & 17 & 1.6 & 1,028 & 18 & 1.8 \\
\hline \multicolumn{2}{|c|}{$\begin{array}{l}\text { Mean number of } \\
\text { crabs caught }\end{array}$} & $149 \pm$ & $49^{a}$ & & $162 \pm$ & $48^{a}$ \\
\hline
\end{tabular}
distances from the traps and the corresponding numbers recaptured during 11 sets for each fishing period. (Recaptures pertain only to traps associated with their own release lines.)

a $95 \%$ confidence limits. 


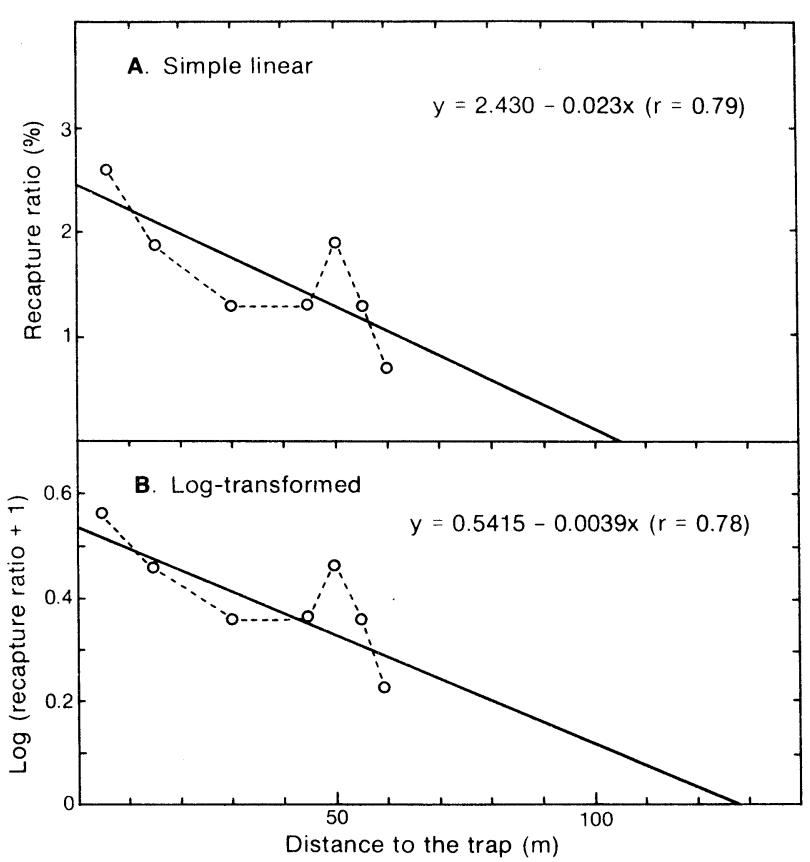

Fig. 3. Relations between recapture rate of tagged crabs and distance of their release from the trap for the 24-hr fishing period: (A) ordinary linear regression, and (B) linear regression of log-transformed variables.

areas that are influenced by the bait odor. With the effective distance $D_{e}$ being equal to one-half $D_{\max }$, the corresponding effective fished areas are $8,800 \mathrm{~m}^{2}$ and $15,200 \mathrm{~m}^{2}$. However, according to the method of Sokal and Rolph (1981), the $95 \%$ confidence interval for $D_{\max }$ is very large, the limits being 53 to $846 \mathrm{~m}$ for the linear model and 73 to $6,685 \mathrm{~m}$ for the logarithmic model. The results of the 48-hr experiment were much less definite (Fig. 4), because the correlations were not significant and distance from the trap explained no more than $18 \%$ of the variability in recapture rates.

The degree to which tagged crabs intermingled was quite high (Table 2). A part from the first day of the experiment, about $70 \%$ of the recaptured crabs were taken in traps outside their lines of origin. Evidently, the tagged crabs moved about to a great extent (Table 3 ), because some were taken up to $900 \mathrm{~m}$ from their release sites in $24 \mathrm{hr}$ and up to $3,300 \mathrm{~m}$ away in $48 \mathrm{hr}$.

Analysis of the data by the Schnabel tag-recapture method (Ricker, 1980) gave an estimate of 64,000 vulnerable crabs in the experimental area, with $95 \%$ confidence limits from 48,800 to 90,700 individuals (Table 4). For the experimental surface area of $5.1 \mathrm{~km}^{2}$, these numbers correspond to an average density of 6.3 crabs per $500 \mathrm{~m}^{2}$, with variation from 4.8 to 8.9 crabs per $500 \mathrm{~m}^{2}$. For the average catch of 149 crabs in the 24-hr fishing period (Table 1), the effective fished area of a trap in operation for $24 \mathrm{hr}$ is estimated to be between 8,400 and $15,500 \mathrm{~m}^{2}$, the average being 11,800

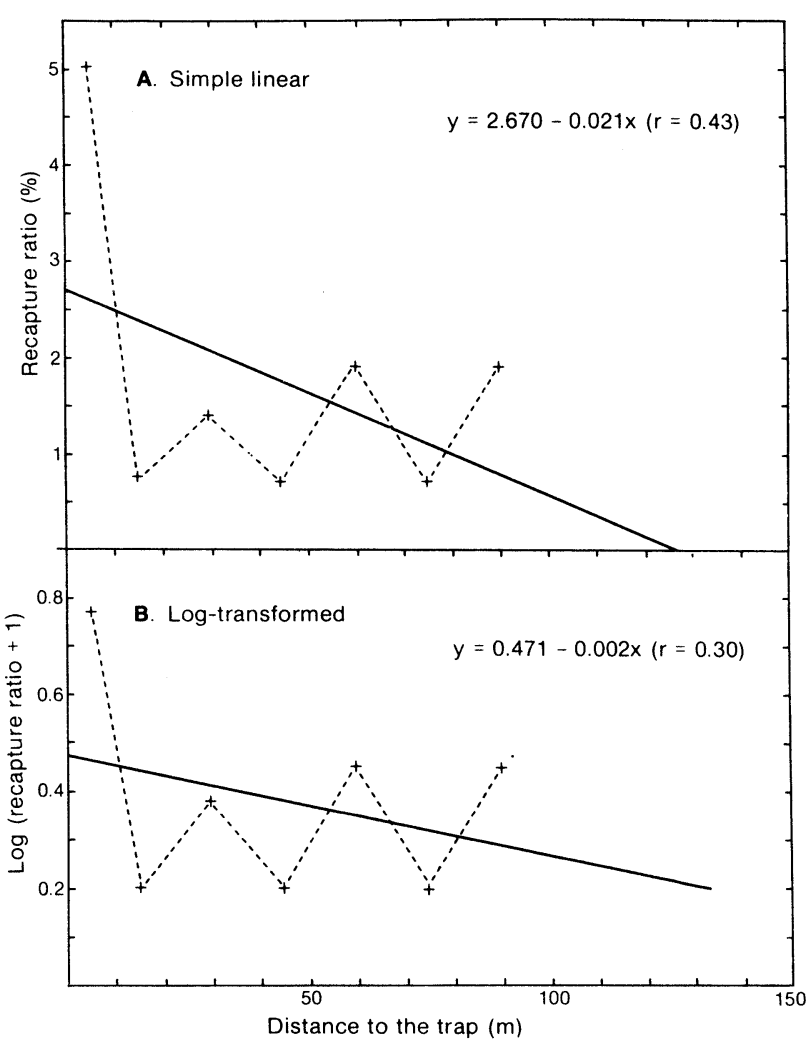

Fig. 4. Relations between recapture rate of tagged crabs and distance of their release from the trap for the 48-hr fishing period: (A) ordinary linear regression, and (B) linear regression of log-transformed variables.

$\mathrm{m}^{2}$. This range of estimates is similar to that derived earlier by assuming that $D_{e}$ was equal to one-half $D_{\max }$ $\left(8,800\right.$ to $\left.15,200 \mathrm{~m}^{2}\right)$.

\section{Discussion}

In principal, the tagging method described above appears efficient. For the $24-\mathrm{hr}$ fishing period, catches of tagged crabs decreased with increasing distance of their release sites from the traps, which confirms the hypothesis that the effect of a stimulus (bait's odor) is a function of its intensity. The estimated effective fished area $\left(8,800-15,200 \mathrm{~m}^{2}\right)$, as measured from the regressions of recapture rate on distance of released crabs from the trap, appears realistic for the 24-hr fishing period. The upper limit of the range is similar to the area $\left(15,000 \mathrm{~m}^{2}\right)$ suggested by Greendale and Bailey (1982) for the same kind of trap without any mention of their method of calculation. Because the method of determining the effective fished area, in this study, by extrapolation of straight lines is a somewhat hazardous operation and the confidence limits are very large, the results must be considered as gross approximation. However, the range of estimates of the effective fished area is very similar to that obtained by the Schnabel tagging-recapture method $\left(8,400-15,500 \mathrm{~m}^{2}\right)$. 
TABLE 2. Numbers and percentages of tagged crabs recaptured in traps other than those associated with their own release lines.

\begin{tabular}{cccc}
\hline \multirow{2}{*}{$\begin{array}{c}\text { Date of } \\
\text { experiment }\end{array}$} & \multicolumn{2}{c}{ Recaptures } & $N_{\mathrm{O}} / \mathrm{N}_{\mathrm{T}}$ \\
\cline { 2 - 4 } & $\mathrm{N}_{\mathrm{T}}$ (total) & $\mathrm{N}_{\mathrm{O}}$ (outside) & $(\%)$ \\
\hline 09 Oct & 8 & 3 & 37.5 \\
10 Oct & 31 & 22 & 71.0 \\
11 Oct & 20 & 13 & 65.0 \\
12 Oct & 51 & 37 & 72.5 \\
Total & 110 & 75 & 68.2 \\
\hline
\end{tabular}

TABLE 3. Residual distances travelled by crabs before recapture, excluding those caught in traps associated with their own release lines.

\begin{tabular}{ccrcc}
\hline \multirow{2}{*}{$\begin{array}{c}\text { Days of } \\
\text { freedom }\end{array}$} & $\begin{array}{c}\text { No. of } \\
\text { crabs }\end{array}$ & \multicolumn{3}{c}{ Distance travelled $(\mathrm{m})$} \\
\cline { 3 - 5 } & 4 & 530 & 320 & 870 \\
\hline 1 & 27 & 590 & 280 & 3,300 \\
2 & 36 & 2,350 & $360^{\mathrm{a}}$ & $5,950^{\mathrm{b}}$ \\
\hline 2 & & & & \\
\hline
\end{tabular}

Recaptured after 3 days.

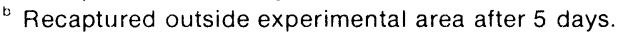

TABLE 4. Estimated population size of crabs in the experimental area by the Schnabel tagging and recapture method.

\begin{tabular}{lcccc}
\hline $\begin{array}{c}\text { No. of } \\
\text { tagged } \\
\text { crabs } \\
\left(\mathrm{M}_{\mathrm{t}}\right)\end{array}$ & $\begin{array}{c}\text { Catch } \\
\text { of } \\
\text { crabs } \\
\left(\mathrm{C}_{\mathrm{t}}\right)\end{array}$ & $\begin{array}{c}\text { Tagged } \\
\text { crabs } \\
\text { recaptured } \\
\left(\mathrm{R}_{\mathrm{t}}\right)\end{array}$ & $\begin{array}{c}\text { Estimated } \\
\text { population } \\
\text { size } \\
\left(\mathrm{N}_{\mathrm{t}}\right)\end{array}$ \\
\hline 09 Oct & 684 & 790 & 8 & 60,040 \\
10 Oct & 1,350 & 722 & 31 & 30,459 \\
11 Oct & 1,883 & 453 & 20 & 40,619 \\
12 Oct & 2,258 & 2,069 & 51 & 89,842 \\
\hline Mean population size, $\Sigma\left(\mathrm{C}_{\mathrm{t}} \cdot \mathrm{M}_{\mathrm{t}}\right) / \Sigma \mathrm{R}_{\mathrm{t}}$ & & 64,000 \\
95\% confidence limits $(\mathrm{df}=3)$ & & $48,800-90,700$ \\
\hline
\end{tabular}

The range of density in this experiment (4.8-8.9 crabs $/ 500 \mathrm{~m}^{2}$ ), based on population estimates by the Schnabel method, is very similar to that reported by Miller (1975) from bottom photography in Conception Bay, Newfoundland $\left(5.2-9.2 \mathrm{crabs} / 500 \mathrm{~m}^{2}\right)$. The fact remains, however, that certain basic requirements of the method may not have been met. The method assumes that random mixing of tagged and untagged crabs takes place and that the probability of capture remains the same for the tagged and untagged individuals (type C error, according to Ricker, 1980). The considerable mobility that was observed among the crabs in this experiment indicates that the first criterion may have been fairly well met. The second criterion concerning equal probability of capture may not have been well met, because the experimental process increased the probability that certain tagged crabs be recaptured by specific traps. This could result in a decrease in the apparent density and, consequently, in overestimation of the effective fished area.
No conclusion can be obtained from the experiment involving the 48-hr fishing period. Because of the extended fishing time and the evident mobility of the crabs, some individuals that were outside the bait's odor plume when the traps were set could have haphazardly entered the area while searching for food.

The major problem concerns the low recapture rate of tagged crabs ( $<5 \%$ overall) which casts some doubt on the validity of the conclusions. The principal cause of the low rate may lie in the technique itself. The trauma of the tagging operation and the possible difficulty of escaping from the plastic bags must surely have contributed to reducing the activity level of the crabs. The length of the recuperation period, coupled with a hiding reaction, could also have reduced the crabs' activity and thus their likelihood of recapture. One improvement in the tagging technique would be the use of self-opening cages instead of bags. Other reasons for the low recapture rate could be biological in nature. The bait odor is assumed to be the principal, if not the only, stimulus which attracts the crabs to the trap, but this may not be the case. Factors which might cause disinterest in the bait, and thus affect the catching process, include the presence of other suitable prey, migrations, molting, reproductive activity, aggressive reactions, etc. An element which has not been taken into account is hydrology (notably currents) which may not only perturb the behavior of crabs but also modify the odor plume. The presence of currents could seriously affect the results and consequently the estimation of the effective fished area which is assumed to be circular.

The experiments indicate that the area of influence of a baited trap may be quite extensive. The observations that certain tagged crabs travelled $800 \mathrm{~m}$ in $24 \mathrm{hr}$ and as far as $3,000 \mathrm{~m}$ in $48 \mathrm{hr}$ before being recaptured lead to the belief that the area of influence is much greater than those which may be surmised from the studies of Miller (1975) and Caddy (MS 1977). The latter author based his model on diffusion of the bait odor in water. The results of the experiments in this paper indicate that, in commercial operations, there must be a fair amount of interaction among traps, even when they are spaced at distances of 100 to $200 \mathrm{~m}$ apart.

The biological parameters of the population appear to be extremely important factors. They are intervening, if not predominant, contributors to the vulnerability of individual crabs and, consequently, to the variability of catch success. These parameters, which may or may not be measurable, induce a high degree of variability in the estimates. It seems, therefore, that the concepts of effective fished area and influential area of the trap are essentially theoretical. Problems with their measurement limit considerably 
the practicality of using baited traps for stock assessment purposes.

\section{Acknowledgements}

We greatly appreciate the financial assistance of the Conseil de Recherches en Sciences Agricoles du Quebec for this project. We also thank Gilles Fortin for the field work, Joelle Bussieres for the illustrations and Beverly Edwards for translation of the manuscript which was originally prepared in French.

\section{References}

CADDY, J. F. MS 1977. Some considerations underlying definitions of catchability and fishing effort in shellfish fisheries, and their relevance for stock assessment purposes. ICES C. M. Doc., No. K:18, $22 \mathrm{p}$.

EGGERS, D. M., N. A. RICHARD, O. G. CHAPMAN, and R. R. WHITNEY. 1982. A methodology for estimating area fished for baited hooks and traps along a ground line. Can. J. Fish. Aquat. Sci., 39: 448-453

FARMER, A. S. D., and M. H. AL-ATTAR. 1981. A design for a simplified releasing cage for marked shrimp or fish. Kuwait Bull. Mar. Sci., 2: 265-269.

GREENDALE, R., et R. F. J. BAILEY. 1982. Résultats d'inventaires du crabe des neiges (Chionoecetes opilio) dans l'estuaire et le Golfe Saint-Laurent. Rapp. Tech. Can. Sci. Halieut. Aquat., No. 1099, $40 \mathrm{p}$
HANCOCK, D. A. 1974.. Attraction and avoidance in marine invertebrates: their possible role in developing artificial bait. ICES $J$. Cons., 35: 328-331.

MACKIE, A. M. 1973. The chemical basis of food detection in the lobster Homarus gammarus. Mar. Biol., 21: 103-108.

MACKIE, A. M., P. T. GRANT, R. G. J.SHELTON, B. T. HEPPER, and P. R. WALNE. 1980. The relative efficiences of natural and artificial baits for the lobster Homarus gammarus: laboratory and field trials. ICES J. Cons., 39: 123-129.

MCLEESE, D. W. 1970. Detection of dissolved substances by the American lobster (Homarus americanus) and olfactory attraction between lobsters. J. Fish. Res. Board Can., 27: 1371-1378.

MILLER, R. J. 1975. Density of the commercial spider crab Chionoecetes opilio, and calibration of effective area fished per trap using bottom photography. J. Fish. Res. Board Can., 32: 761-768.

1978. Entry of Cancer productus to baited traps. ICES J. Cons., 38: 220-225.

1979. Saturation of crab traps: reduced entry and escapement. ICES J. Cons., 38: 338-345.

1981. Strategies for improving crab trap hauls. World Fish., 30(10): 51.

RICKER, W. E. 1980. Calcul et interpretation des statistique biologiques des populations de poisson. Bull. Fish. Res. Board Can., 191F: $409 \mathrm{p}$.

RODHOUSE, D. M. 1984. Experimental fishing for the spider crab, Maia squinado: sea and laboratory trials. J. Mar. Biol. Assoc. U.K., 64: 251-259.

SOKAL, R. R., and F. J. ROLPH. 1981. Biometry (2nd edition), W. H. Freeman and Co., San Francisco, 859 p.

TALBOT, J. W., and H. SENDNER. 1973. Consideratıon of the horizontal diffusion process during the experiment. ICES Rap. Proc.Verb., 163: 59-75.

WATSON, J. 1970. Tag recaptures and movements of adult male snow crabs, Chionoecetes opilio (O. Fabricius), in the Gaspé region of the Gulf of St. Lawrence. Fish. Res. Board Can. Tech. Rep., 204: 10 p. +5 fig. 